\title{
Pharmacists' viewpoint towards their professional role in healthcare system: a survey of hospital settings of Pakistan
}

\author{
Nabeel Khan ${ }^{1 *} \mathbb{D}$, Ken McGarry², Atta Abbas Naqvi ${ }^{3}$, Muhammad Shahid lqbal ${ }^{4}$ and Zaki Haider ${ }^{5}$
}

\begin{abstract}
Background: Pharmacy service is an essential part of a healthcare system. The profession of pharmacy is well recognized and is practiced to its full potential in developed countries however, it is underutilized in developing countries such as Pakistan. The recognition of pharmacist's role as healthcare professional is limited. This study aimed to document pharmacists' attitude towards their role in Pakistan's healthcare system, their experience with doctors and their perceptions towards involvement in medicines management.
\end{abstract}

Methods: A 4-month cross-sectional survey (Jan - Apr 18) was conducted targeting pharmacists practising in 26 tertiary care hospitals across Pakistan using a developed and validated questionnaire in both Urdu/English languages. Chi square $\left(x^{2}\right)$ test was used to report any associations between independent variables, i.e., education, type of hospital and work experience and, dependent variables, i.e., pharmacists' attitudes, experience, and perception. A $p$-value of $\leq 0.01$ with value of Cramer's $V \geq 0.3$ was considered cut-off for establishing statistical significance. The study was approved by ethical committee and local hospital committees.

Results: Three hundred ninety-six questionnaires were returned out of 500 , i.e., response rate $=87.9 \%$. Most participants (92.2\%) interacted with doctors at least once daily. Most interactions were related to drug availability inquiry (72.5\%). Most pharmacists (91.4\%) mentioned that pharmacy duties are mostly clinical in nature. $93.4 \%$ of the respondents indicated that pharmacists are reliable source of information regarding general medicines. Furthermore, $87.4 \%$ reasoned inadequate training for not being able to discuss issues of clinical nature with doctors.

Conclusion: Pharmacists were willing to perform their duties and provide healthcare benefits to patients however, they seemed sceptical of advanced clinical pharmacy roles such as intervening in prescriptions and medication therapy, consultations and prescribing. There is a need to increase awareness regarding pharmacist's role. Therefore, it would be helpful if trainings and seminars are conducted on the importance of clinical pharmacy to improve the pharmacy services in Pakistan's healthcare system.

Keywords: Pharmacists, Clinical pharmacists, Hospital pharmacy service, Clinical pharmacy service, Pakistan

\footnotetext{
* Correspondence: nabeel.khan@research.sunderland.ac.uk

${ }^{1}$ School of Pharmacy and Pharmaceutical Sciences, University of Sunderland, Sunderland, UK

Full list of author information is available at the end of the article
}

(c) The Author(s). 2020 Open Access This article is licensed under a Creative Commons Attribution 4.0 International License, which permits use, sharing, adaptation, distribution and reproduction in any medium or format, as long as you give appropriate credit to the original author(s) and the source, provide a link to the Creative Commons licence, and indicate if changes were made. The images or other third party material in this article are included in the article's Creative Commons licence, unless indicated otherwise in a credit line to the material. If material is not included in the article's Creative Commons licence and your intended use is not permitted by statutory regulation or exceeds the permitted use, you will need to obtain permission directly from the copyright holder. To view a copy of this licence, visit http://creativecommons.org/licenses/by/4.0/ The Creative Commons Public Domain Dedication waiver (http://creativecommons.org/publicdomain/zero/1.0/) applies to the data made available in this article, unless otherwise stated in a credit line to the data. 


\section{Introduction}

The profession of pharmacy has evolved from a productfocused practice to a patient-oriented one [1]. In general, the primary duties of the pharmacist include providing drug information, medicines management, preparation and dispensing of medicines, counselling of patients, and formulating pharmaceutical care plan for patients [2]. Pharmaceutical care plan is an individualized service provided by pharmacist that aims to improve the quality of patient's health $[3,4]$. Pharmaceutical care involves a collaborative relationship between the pharmacist and the physicians to improve the health status of patients [5]. It was envisioned that in future, pharmacists would be greatly involved in clinical and administrative roles and, their traditional roles of pill counting, packaging, and dispensing would be performed by technicians and trainees [6]. Literature suggests that pharmaceutical care practice has a substantial positive effect on healthcare and disease management in developed countries [7, 8]. However, the situation is different in developing countries as the application of pharmaceutical care is hindered due to time constraints, lack of standard reimbursement, less access to patients' records, poor communication among healthcare professionals, insufficient number of qualified pharmacists and absence of policies [8].

A pre-requisite to establishing effective pharmaceutical care services would be the greater involvement of hospital pharmacist as a member of allied health team with increased interaction with other healthcare professionals. Effective implementation of this service requires an understanding of a hospital pharmacist's perception towards the concept of pharmaceutical care, their role in direct patient care and, the extent and level of interaction with other healthcare professionals [9]. The traditional role of pharmacist has always been procurement and inventory management of medicines along with ensuring their safety and efficacy [10]. However, with the introduction of 'Pharmaceutical care' concept by Hepler and Strand during the 90s, the tradition role of pharmacist has transcended from medicine provider to a patient care provider [11]. During the last few decades, pharmacists have practiced pharmaceutical care to improve patients' treatment outcomes and maximize the benefits of medication therapy to patients $[5,12]$.

According to the World Health Organization (WHO), pharmacists are expected to advise allied health team regarding medication therapy management in patient care and must have specialized knowledge and skills needed to execute clinical pharmacy services [13, 14]. In Pakistan, the health authorities have resolved to introduce the pharmaceutical care services within the healthcare system to improve patient's quality of life [15]. However, pharmaceutical care model is a novel concept within pharmacy practice domain and is not clear to a majority of health professionals and public [16]. Besides, there are few pharmacists with knowledge of pharmaceutical care and clinical pharmacy services in healthcare system. In addition, clinical guidelines are either not updated or not available, that could highlight pharmacist's role in patient care. These are few notable determinants of an enhanced clinical role of pharmacist in Pakistan's healthcare system $[9,17]$. In addition, there is an acute shortage of pharmacists in all healthcare sectors of the country. Hospital pharmacists are involved to a greater extent in traditional pharmacy services and administrative activities. Furthermore, it has been observed that pharmacy graduates in Pakistan preferred to join pharmaceutical marketing and sales jobs [17-19].

Pharmacy curriculum in Pakistan has traditionally been inclined towards drug manufacturing and dispensing. During the last decade, the healthcare policymakers envisioned a clinical role of pharmacist and since then, the pharmacy curriculum has been modified to incorporate courses related to clinical pharmacy practice [2022]. Moreover, the current pharmacy practice model in Pakistan requires modifications concerning collaborative practice supported by evidence and should have a clear perspective in its application and conceptualisation [23, 24]. As this paradigm is novel in Pakistan, it requires more planning for future perspectives suitable to the country's health policies. At the same time, it is imperative to find out what pharmacists perceive about pharmaceutical care service and their supposed engagement with the other medical staff, to understand the determinants that hinder their clinical role in Pakistani healthcare settings.

Available literature highlights that interprofessional relationship between doctors and pharmacists was not satisfactory in the past. One of the reasons was education and training of pharmacists [20-24]. Azhar and colleagues identified that the primary reasons for doctors' low expectations with pharmacists were deficiency in knowledge of therapeutics and inadequate clinical pharmacy training [23]. In addition, Khan and colleagues highlighted that workplace and experience of healthcare professionals could influence views towards pharmacists and their services [24]. Hence, having pharmacy education that includes clinical courses is vital in shaping the perception and expectations of pharmacists regarding healthcare system of Pakistan.

In the past, adequate attention was not paid to update pharmacy curriculum and thus, it could not contribute significantly in achieving the healthcare objectives. The 4-year Bachelor of Pharmacy (BPharm) degree was upgraded to a 5-year Doctor of Pharmacy (PharmD) program by the Higher Education Commission (HEC) of Pakistan in 2004. The course introduces an intensive knowledge of clinical aspects of pharmacy. The updated 
program had courses that provided the knowledge of; clinical and social aspects of pharmacy, such as drug abuse, geriatric pharmacy, patient counselling, patient compliance, research methods, and evidence-based medicine, that have been largely ignored previously [9, 21, 22].

The health authorities of Pakistan should implement pharmaceutical care practices in the health system of the country, to promote safe use of medicines and improve patients' quality of life [23, 24]. The present study was conducted to evaluate the acceptability of pharmacists as a patient care provider, their interaction with the doctors and, their perception about performing medicines management services. Thus, the study evaluated pharmacists' viewpoint regarding their professional role in the healthcare system of Pakistan.

\section{Methodology}

\section{Study objective}

The primary objective of this study was to document attitude of pharmacists towards their role in Pakistan's healthcare system, their experience with doctors and their perceptions towards involvement in medicines management.

\section{Study design, duration, and venues}

This study was a cross-sectional survey that was conducted for a period of 4 months, i.e., from January 2018 up to April 2018. Pakistan is located in South Asia and hosts a population over 220 million. The healthcare system of Pakistan consists of state funded and private sector healthcare facilities [25]. There are 968 state funded hospitals across 8 administrative units of the country. Since the state funded healthcare structure is inadequate to fulfil healthcare needs of the population, most of Pakistanis utilize private sector hospitals as well [21]. The study was conducted in 122 tertiry care hospitals in 27 cities of Pakistan that were in 6 administrative units of the country (Fig. 1).

\section{Target population and eligibility criteria}

The target population was pharmacists working in hospital settings in several cities of Pakistan. The eligibility criteria of pharmacists were adopted from Naqvi et al., i.e., licensed pharmacists who were currently working in healthcare settings of Pakistan for at least 1 year [14, 23]. All licensed pharmacists working in the pharmaceutical industry, academia and community pharmacies were excluded. They were excluded from study since they were not working in the healthcare settings and may have different perceptions that may not be representative.

\section{Sampling strategy and sample size calculation}

Data collection was conducted using convenience sampling technique due to the unavailability of a database that could highlight the exact number of pharmacists practising in various hospitals across Pakistan. The study sample size was estimated using an online sample size calculator (RAOSOFT) [26]. As per the country's pharmaceutical data obtained from WHO 2010 report, there were roughly 10,000 licensed pharmacists working in all settings of Pakistan [25]. This figure was considered as target population. A 5\% margin of error and 95\% confidence level was set. The required sample size was 370. A $2 \%$ drop-out rate $(N=8)$ was added to yield the final number of 378 pharmacists.

\section{Research instrument development and validation}

The questionnaire was formulated for this study with help from previous literature by a panel of experts including two academicians and two clinical pharmacists $[7,23,24]$. There were four sections in the questionnaire that included demographic information about participants, the interactions of pharmacists with doctors, the reasons for their interactions and, the perception of pharmacists regarding their professional role in Pakistan's healthcare settings. Apart from demographic questions, it included questions related to professional acceptance of pharmacists in the healthcare system, pharmacists' experience of working with doctors and, the involvement of pharmacists in medicines management. The final questionnaire contained a total of 45 items and it took about $25 \mathrm{~min}$ on an average to fill in the response. The options for questions except for demographics were dichotomous, i.e., in yes/no format. The questionnaire was formulated in both English and Urdu languages. The English version of questionnaire is available as a supplementary file (additional file 1: Questionnaire).

The questionnaire was subjected to content validation by a panel of experts that included three academicians, two clinical pharmacists and three pharmacists. Each member of the panel reviewed the questions and indicated them as essential/non-essential. Content validation was conducted using the methodology described by Lawshe and Rungtusanatham [27, 28]. The content validity index was reported at 0.81 which was greater than the cut-off value 0.75 required for establishing validity [27]. The reliability of questionnaire was estimated using Cronbach alpha $(\alpha)$. The overall reliability for all items $(N=45)$ was reported at 0.889 . The intraclass correlation coefficient was 0.889 (95\% CI: 0.873-0.904). The reliability for the section of professional acceptance of pharmacists in the healthcare system that contained 17 items was 0.908 . The intraclass correlation coefficient was 0.908 (95\% CI: 0.894-0.920). Besides, the reliability for the section of pharmacists' experience of working with 


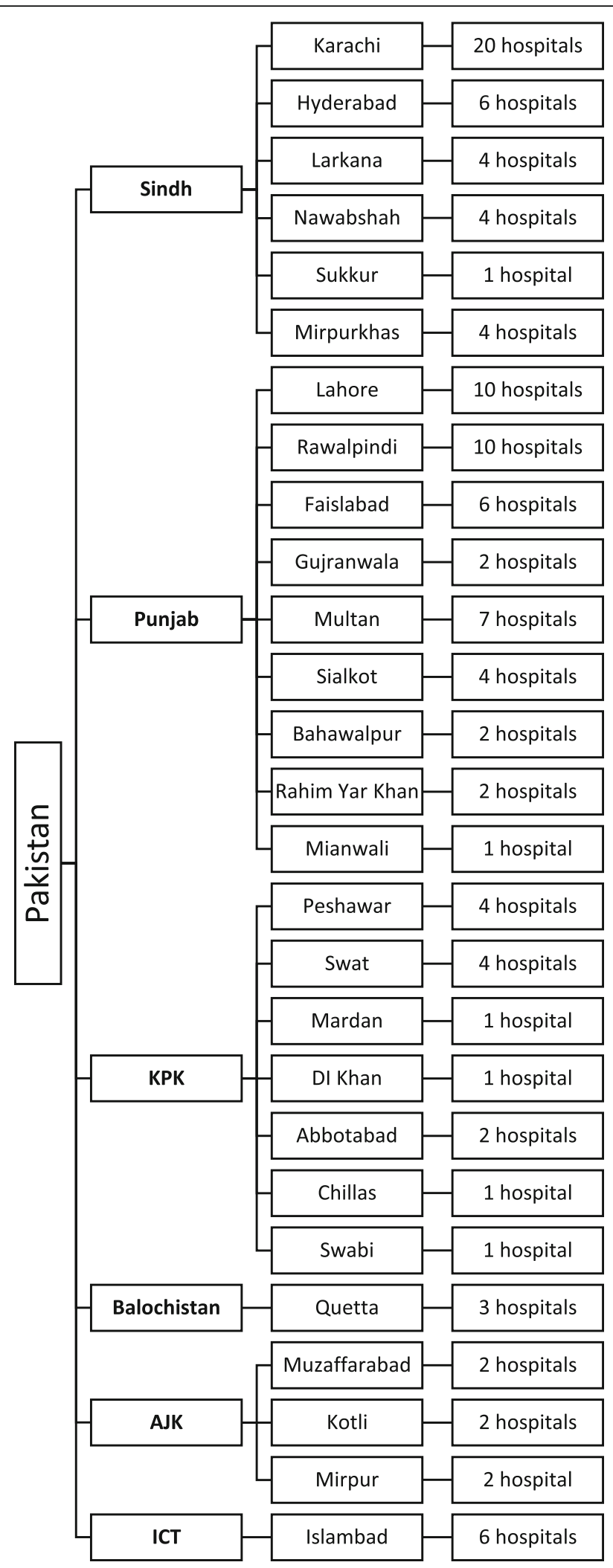

Fig. 1 Study venues 
doctors that had 15 items, was 0.861 and intraclass correlation coefficient was 0.861 (95\% CI: 0.840-0.880). Moreover, the reliability for the section of involvement of pharmacists in medicines management that had 13 items, was 0.831 and intraclass correlation coefficient was 0.830 (95\% CI: 0.810-0.850). All were in acceptable range $[29,30]$.

\section{Data collection}

The questionnaire was delivered as hardcopy by hand and, were either completed at the same date or, collected later as indicated by the respondent. Prior to handing the questionnaire the participants were briefed about study purpose.

\section{Data analyses}

The data were analysed using statistical software, (SPSS, Chicago, IL, USA, version 24.0). The results were reported, as sample count $(\mathrm{N})$ and frequency (\%). Cross tabulation and chi square $\left(\mathrm{X}^{2}\right)$ test was applied to assess the association between the independent variables (education, type of hospital and experience of pharmacists) and dependent variables (attitude, experiences of pharmacists with doctors and involvement of pharmacists in medicines management in the hospitals). The cut-off for statistical significance was $p$-value $\leq 0.01$ with value for Cramer's $V \geq 0.3$. A $p$-value of $\leq 0.01$ was set to reduce the likelihood type 1 errors [31]. The Cramer's V indicated the strength of association and the value ranged from 0 to 1 with latter indicating a strong association. It was therefore selected as one of the cut-off criteria [32].

\section{Consent and ethics approval}

All those who agreed to participate had to provide their consent before data collection. The study was approved by the Research Ethics Committee of the University (Reference Number 00286). In addition, approval letters from the local hospitals were also obtained before data collection.

\section{Results}

Of total 500 pharmacists approached, 396 questionnaires were completed giving a response rate of $79.2 \%$, the results of which were then taken forward for analysis. Most respondents were male (64.1\%) and had Pharm. D (Doctor of Pharmacy) degree (74.5\%). Almost equal proportions of respondents worked in state-funded (50.3\%) and private hospitals (49.7\%) respectively. As per the job titles of respondents, most respondents were working in capacity of pharmacist (91.7\%). Among all respondents, almost $60 \%$ had experience of 5-10 years. Majority (66.9\%) were associated with in-patient pharmacy. Almost all (99.2\%) respondents were registered with
Pakistan Pharmacy Council. The demographic information data are tabulated in Table 1.

Upon eliciting opinion of pharmacists as to how they describe the pharmacy job, most of them $(N=362$, 91.4\%) mentioned that pharmacy duties are mostly clinical. However, a small number of pharmacists $(N=34$, $8.6 \%)$ mentioned the duties as technical. In response to the question of how they would describe pharmacy as an occupation, most pharmacists $(N=351,88.6 \%)$ mentioned it as a professional occupation while some pharmacists $(N=20,5.1 \%)$ believed it to be a business profession. Similar number of pharmacists $(N=25,6.3 \%)$ mentioned pharmacy job as both professional and business occupation.

Most participants $(N=365,92.2 \%)$ reported that they interacted with doctors daily while some pharmacists $(N=18,4.5 \%)$ reported that their interactions with doctors were on a weekly basis. Few pharmacists $(N=13$, $3.3 \%$ ) reported that they rarely interacted with doctors during their duty hours. In response to the question regarding most common reasons for these interactions, most pharmacists $(N=287,72.5 \%)$ mentioned drug availability queries while some $(N=39,9.8 \%)$ mentioned queries regarding drug alternatives. A small number of pharmacists $(N=29,7.3 \%)$ mentioned queries related to drug interactions while a similar number of participants $(N=25,6.3 \%)$ highlighted queries regarding dosage. Few pharmacists $(N=16,4 \%)$ mentioned queries related to adverse drug reactions as one of the most common reasons for interactions. The data regarding pharmacists' attitude towards their role in the healthcare system and their experience with doctors are tabulated in Tables 2 and 3. In addition, data related to the perception of pharmacists about their involvement in medicines management are tabulated in Table 4. All items were cross tabulated with three independent variables namely level of education of doctors, the nature of hospitals, and work experience of pharmacist.

\section{Discussion}

Pharmaceutical care is an integral part of pharmacy practice in any healthcare setting, and its application varies from one country to another depending upon health regulations. The pharmaceutical care services are advanced in developed countries and involve pharmacists in more clinical and patient-oriented roles. However, the involvement of pharmacists in pharmaceutical care service and the extent of service coverage is limited in developing countries such as Pakistan as there are less pharmacists employed in hospitals. Their duties at most times, are confined to drug dispensing, procurement, and inventory management services, i.e., traditional pharmacy services [33-39]. It has been mentioned earlier that greater involvement of pharmacist in direct 
Table 1 Participants' information $(N=396)$

\begin{tabular}{|c|c|}
\hline Characteristics & $N(\%)$ \\
\hline \multicolumn{2}{|l|}{ Gender } \\
\hline Male & $254(64.1 \%)$ \\
\hline Female & $142(35.9 \%)$ \\
\hline \multicolumn{2}{|l|}{ Professional Education } \\
\hline Bachelor of Pharmacy/ Master of Pharmacy & $87(22 \%)$ \\
\hline Doctor of Pharmacy (Pharm.D) & $295(74.5 \%)$ \\
\hline Overseas Qualification & $14(3.5 \%)$ \\
\hline \multicolumn{2}{|l|}{ Place of Work } \\
\hline State Funded Hospital & $199(50.3 \%)$ \\
\hline Private Hospital & $197(49.7 \%)$ \\
\hline \multicolumn{2}{|l|}{ Current Job Title } \\
\hline Pharmacist & $363(91.7 \%)$ \\
\hline Senior Pharmacist & $26(6.6 \%)$ \\
\hline Chief Pharmacist & $7(1.8 \%)$ \\
\hline \multicolumn{2}{|l|}{ Years of Experience } \\
\hline Less than 5 years & $68(17.2 \%)$ \\
\hline $5-10$ years & $236(59.6 \%)$ \\
\hline More than 10 years & $92(23.2 \%)$ \\
\hline \multicolumn{2}{|l|}{ Area of Practice } \\
\hline Inpatient & $265(66.9 \%)$ \\
\hline Outpatient & $105(26.5 \%)$ \\
\hline Oncology pharmacy & $26(6.6 \%)$ \\
\hline \multicolumn{2}{|l|}{ State of Practice } \\
\hline Sindh & $143(36.1 \%)$ \\
\hline Punjab & $175(44.2 \%)$ \\
\hline Baluchistan & $9(2.3 \%)$ \\
\hline KPK & $44(11.1 \%)$ \\
\hline Capital Territory & $17(4.3 \%)$ \\
\hline AJK & $8(2.0 \%)$ \\
\hline \multicolumn{2}{|l|}{ Are you registered with Pharmacy Council? } \\
\hline Yes & $393(99.2 \%)$ \\
\hline In process & $3(0.8 \%)$ \\
\hline
\end{tabular}

KPK Khyber Pakhtunkhwa, AJK Azad Jammu and Kashmir

patient care and extensive interaction of pharmacists with allied health members would set the platform for improved pharmaceutical care services thereby benefiting the patients. This could only be achieved when pharmacists are involved in traditional duties to a lesser extent. The traditional duties could be performed by pharmacy technicians [10].

Most pharmacists mentioned that their role was clinically oriented and interacted with doctors on a daily basis. This response was significantly associated with workplace as pharmacists working in state funded hospitals interacted more often with doctors. This occurrence could be attributed to the change in healthcare policy that envisioned such role for pharmacists. This occurrence further highlights that Pakistani pharmacists now have a better understanding of pharmaceutical care and consider themselves as member of allied health team. Besides, they regard their work as clinical and patient-oriented.

Most pharmacists agreed that their role and duties in the primary health practice is of clinical nature. This indicates that they were aware of their role as a healthcare professional and, considered participation in drug prescribing and therapeutic procedures as must. This finding was linked to their education status as graduates with PharmD degree or overseas degree in pharmacy, as opposed to BPharm, had better acceptance towards these tasks. This finding could be attributed to the introduction of PharmD degree with clinical pharmacy courses. It is in line with the concept of enhancing pharmacists' capabilities and allowing them to contribute to the primary healthcare system is being promoted, especially in developing countries $[39,40]$. Henceforth, the introduction of PharmD degree has led to a positive change in pharmacists working in Pakistani healthcare settings. Pharmacists with a PharmD degree were observed to be better acquainted with their clinical responsibilities. Moreover, this finding is also in line with the role envisioned by the WHO for pharmacists, that is, to serve in an advisory capacity for other healthcare professionals in ensuring safe and appropriate use of medicines [14].

The data pertaining to the experience of pharmacists with the doctors highlighted that pharmacists were willing to collaborate with doctors to discuss patients' condition and medication therapy. This occurrence was linked to education status and workplace of pharmacists as pharmacists with PharmD and working in state funded healthcare facilities, were exercising these tasks more often. However, the general perception of doctors was negative. Available evidence indicates that doctors perceived that pharmacists were incapable of providing direct healthcare service to patient [38-40]. This negative perception is still prevalent among doctors despite considering pharmacists as knowledgeable and experts in counseling patients about drug dosage and its safe use [24]. Besides, most patients in Pakistan are unaware that they can consult pharmacists if they experience any drug related problem during therapy $[22,24]$. Due to this negative perception among doctors and public incognizance, the pharmacists have limited opportunities to assume the role of a direct patient care provider and mainly resort to practising managerial and administrative tasks in public and private healthcare sectors.

It was observed that the perception of pharmacists about their role in medicine management was quite positive. The pharmacists believed that they were capable of providing this service however, number of pharmacists who had such expertise and training was low. 


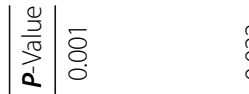
สิ
$\begin{array}{ll}\bar{m} & \bar{\sigma} \\ 0 & 0\end{array}$
范
ָั.
ָָ.
$\stackrel{\circ}{a}$

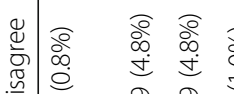

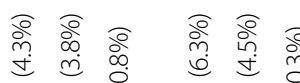

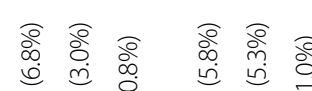

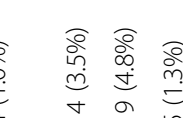

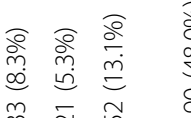

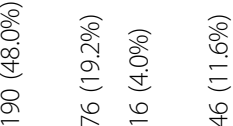

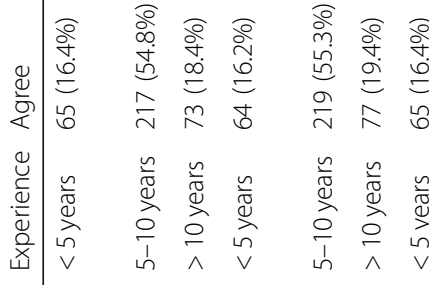

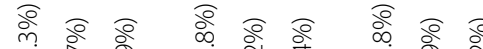

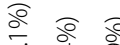

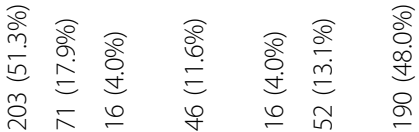

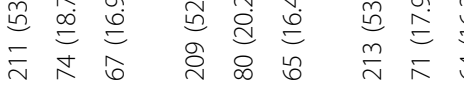

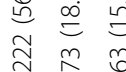

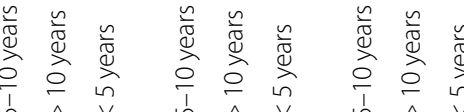

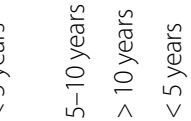

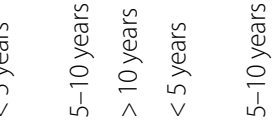

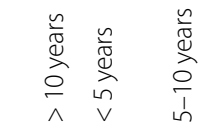

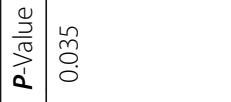
$\infty_{0}^{\infty} \quad$
苍

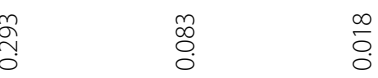
$\stackrel{8}{\circ}$
苜

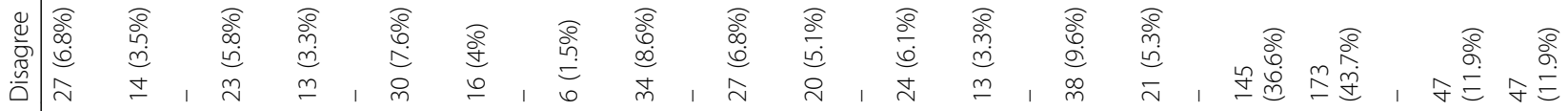

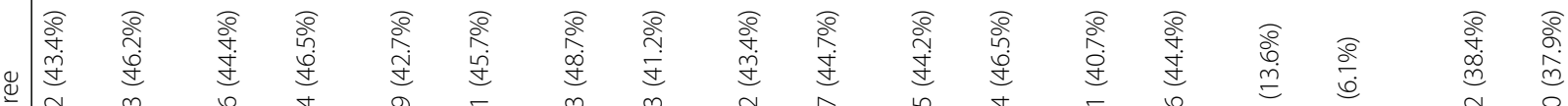

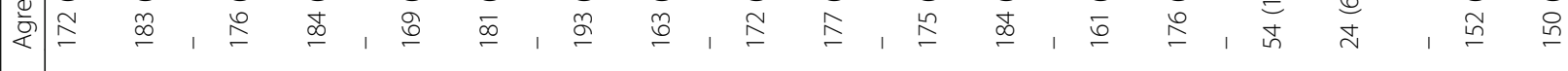

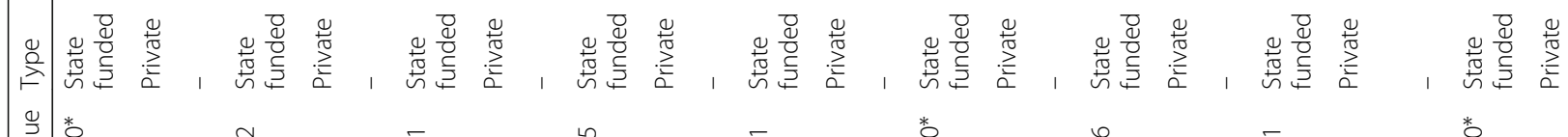
家
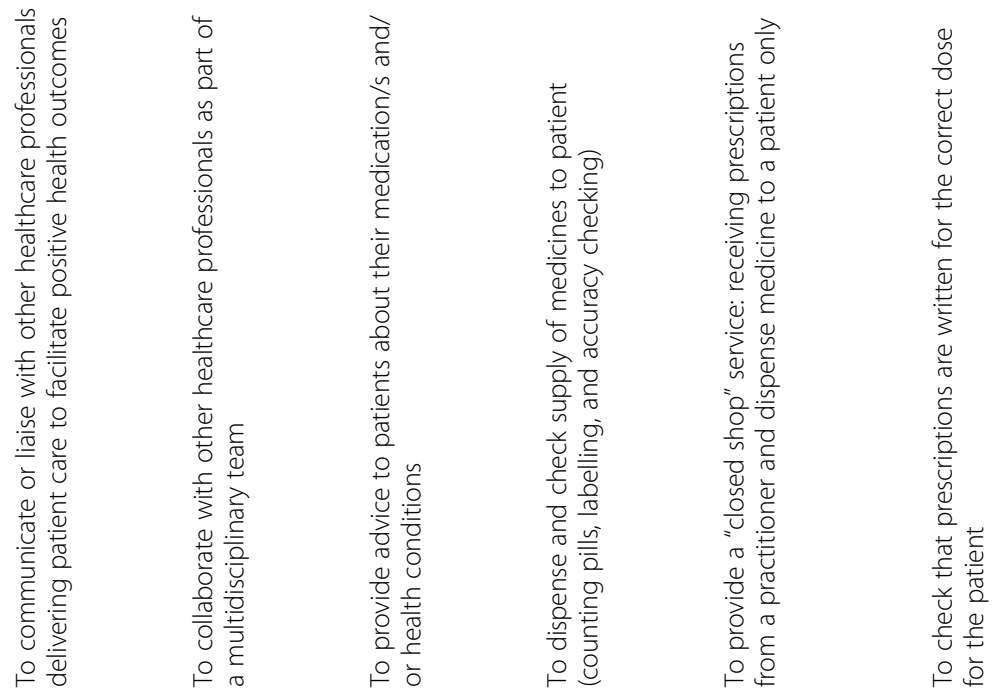


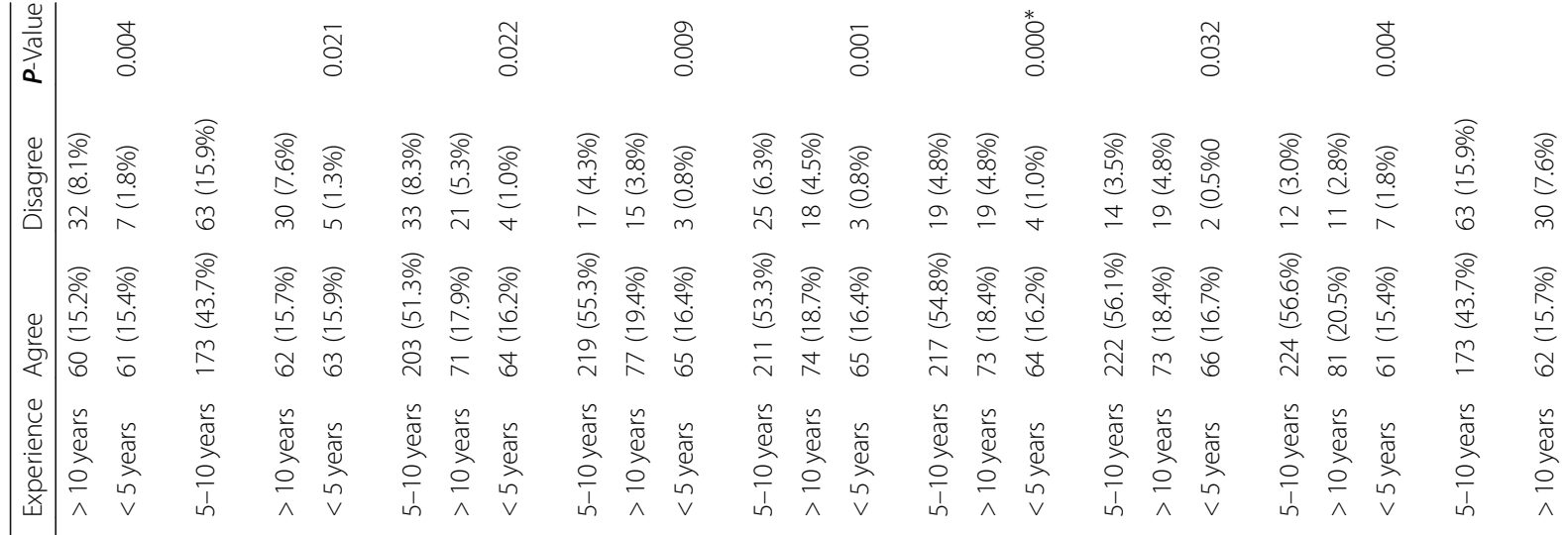

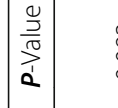

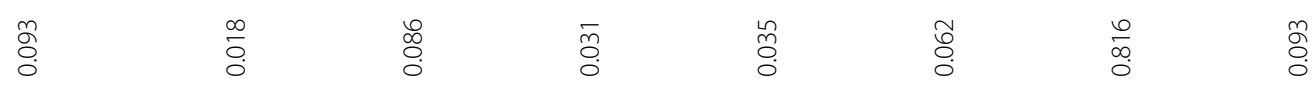

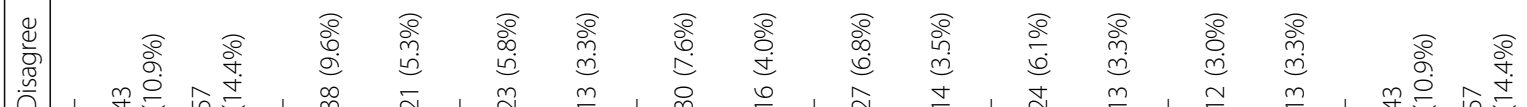

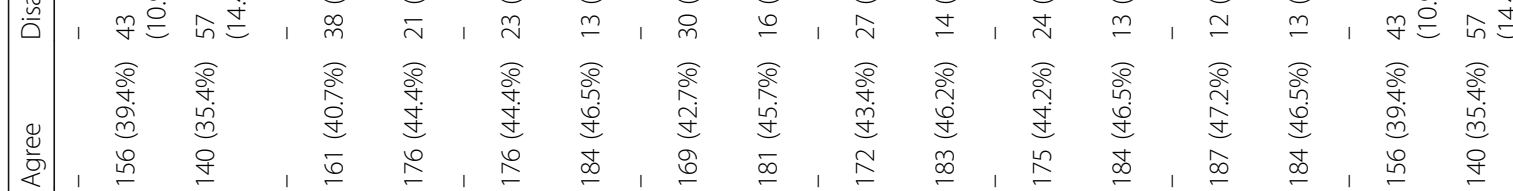

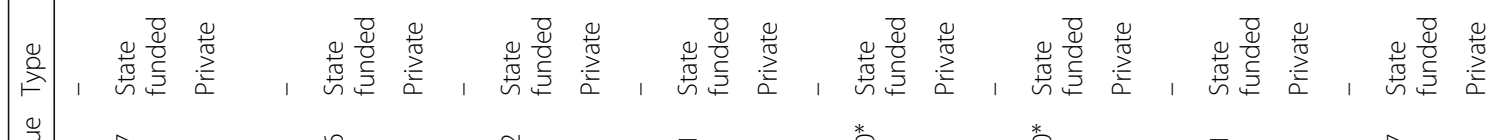

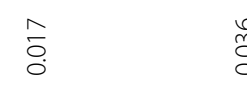 萬 ఠิ

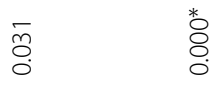

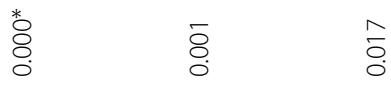

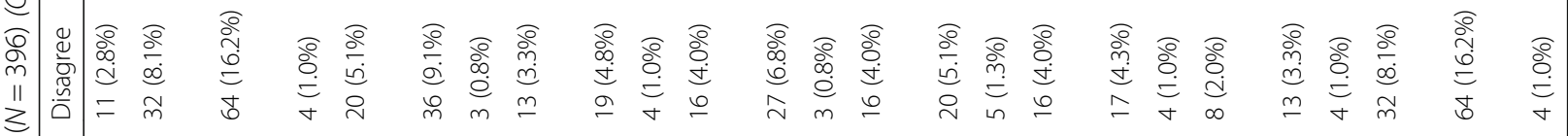

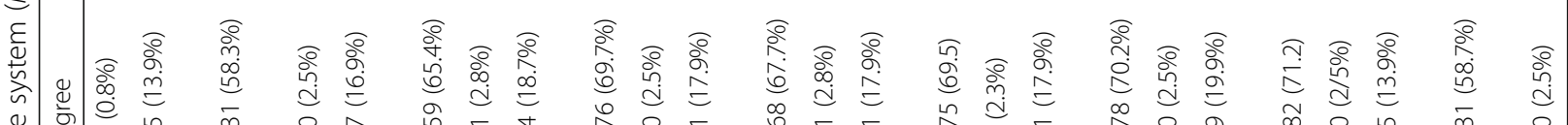

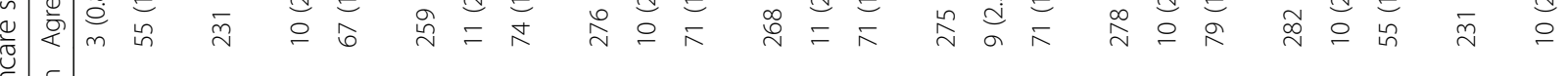

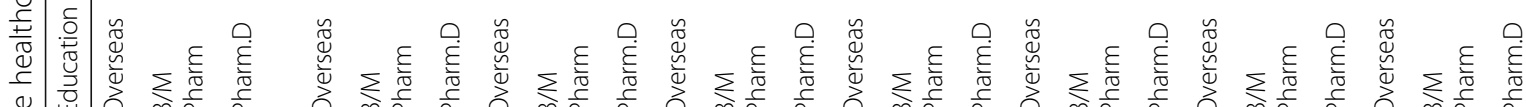

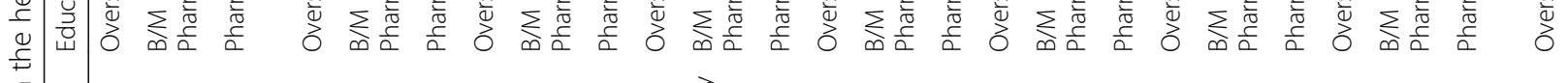




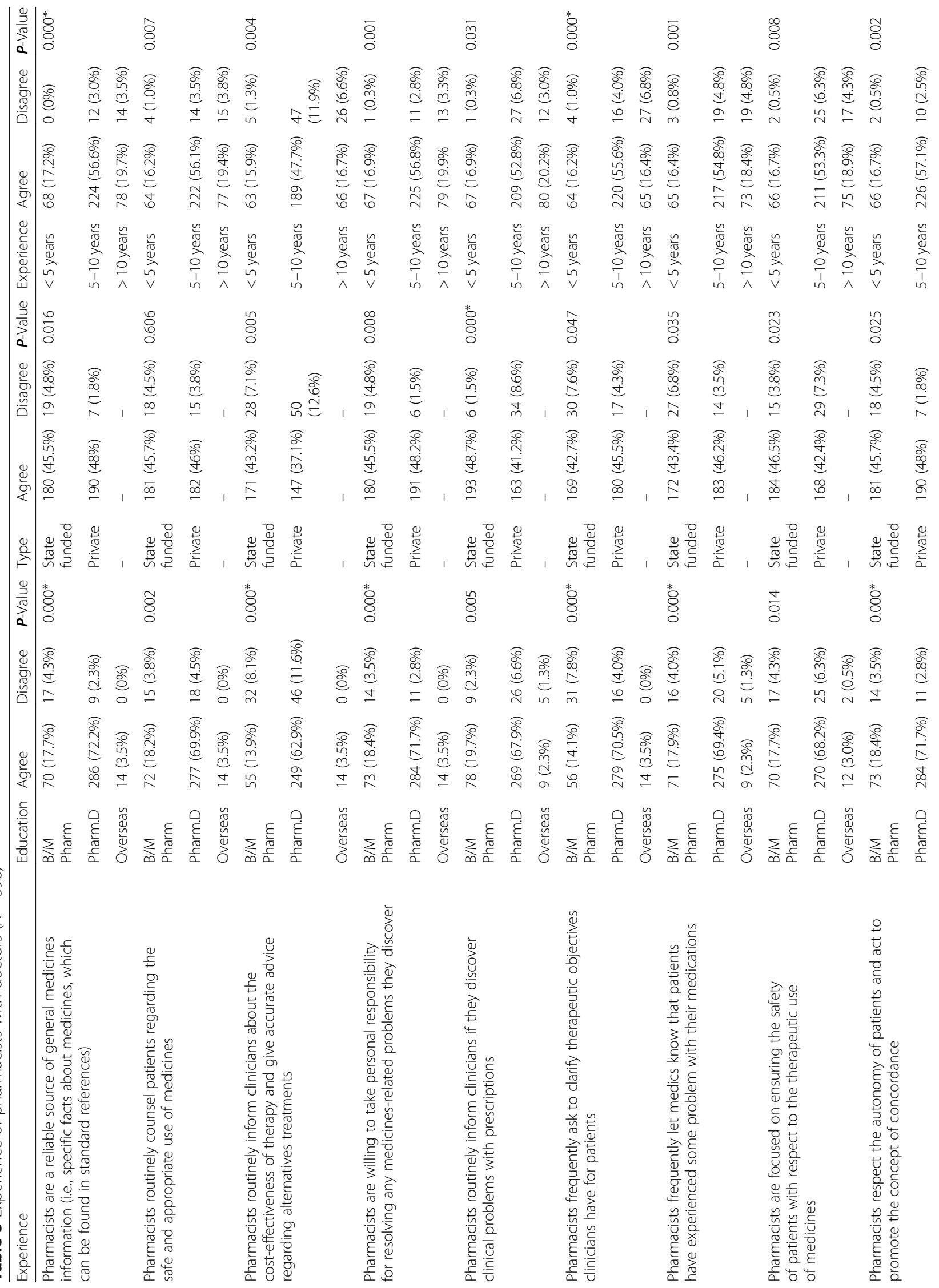




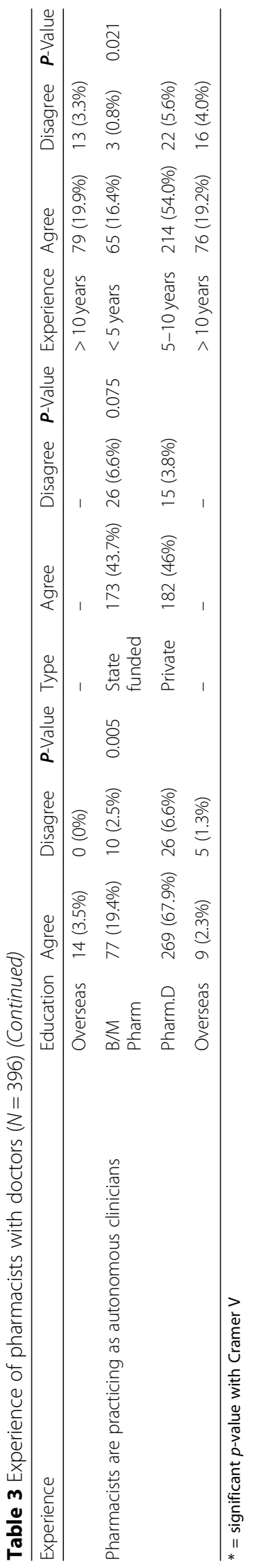




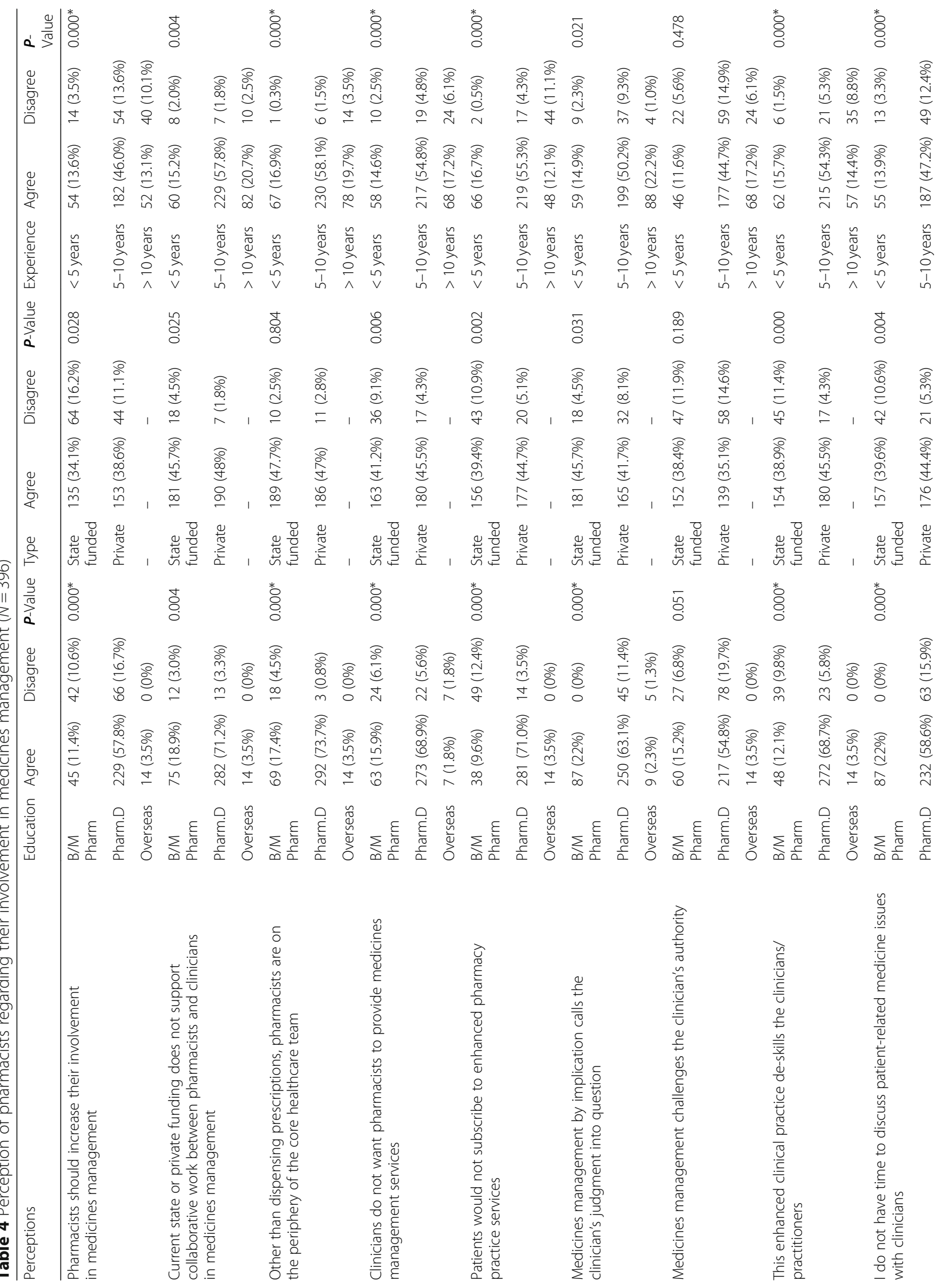




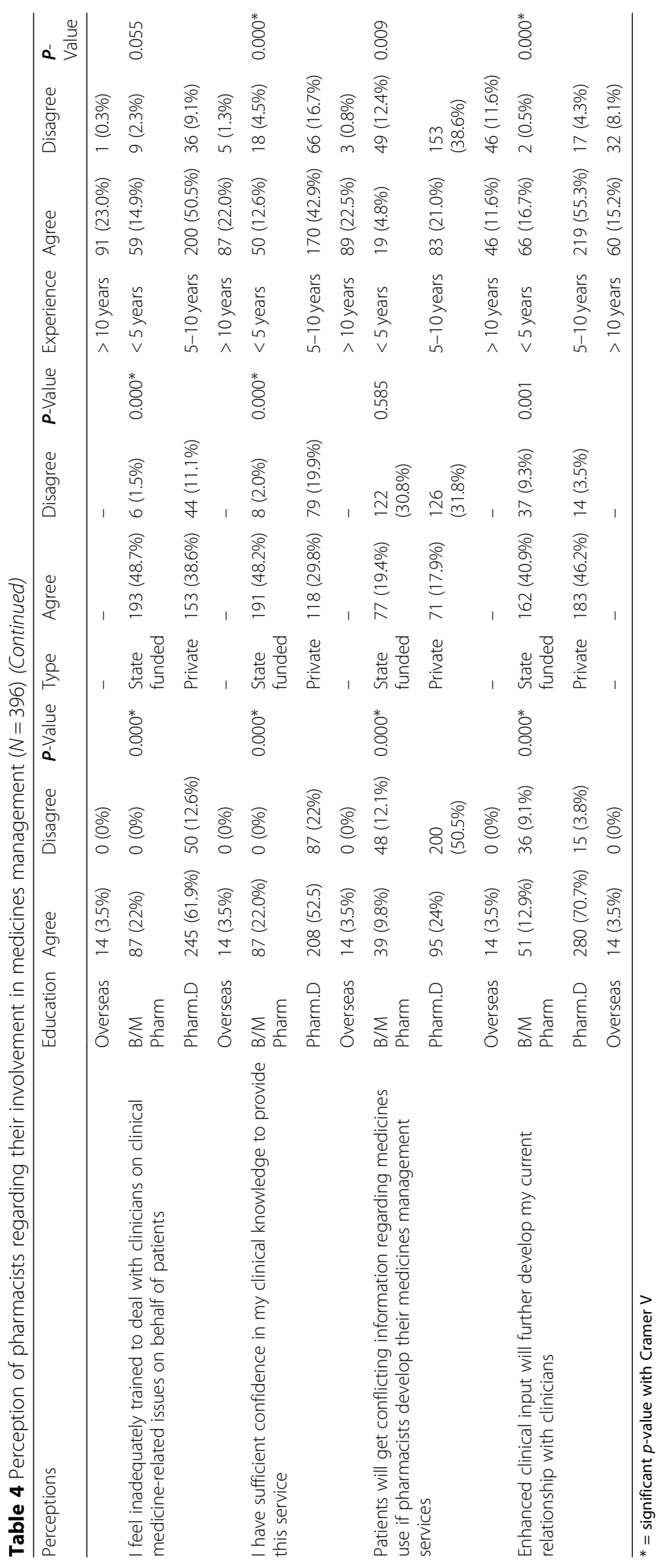


This occurrence is logical given the previous pharmacy curriculum that was focused on educating and training pharmacy graduates in drug manufacturing and dispensing. Thus, pharmacy graduates were mostly inclined towards pharmaceutical manufacturing and medicines dispensing. In India, a neighboring country, the situation was similar to Pakistan's pharmacy education scenario as Indian pharmacy graduates and practicing pharmacists, despite being in a large number, were educated in preparation and dispensing of medicine only [37].

Pakistan's pharmacy curriculum was revised in 2004; the 4 year degree of Bachelor of Pharmacy (B.Pharm) was upgraded to a full-time 5 year Doctor of Pharmacy (Pharm.D) degree program. It was upgraded to strengthen pharmacy graduates' clinical knowledge and practice [37-42]. Studies mentioned that on an average 2587 pharmacy students graduated from Pakistan's pharmacy schools every year. However, this number is not sufficient to meet the demands of pharmacy profession in country's healthcare system [40]. According to available evidence, currently, 8102-10,000 pharmacists are working in Pakistan, of which 55\% are involved in the production of pharmaceuticals, and only $15 \%$ are engaged in community pharmacy [23, 40]. Moreover, in addition to inadequate and untrained resource, doctors were reluctant to engage the pharmacists in medicine prescribing and related tasks $[40,41]$.

There is a need of understanding the role of pharmacists in Pakistani healthcare system and focus on their training and utilization in the health sector. The issue of under-recognized role could be addressed by attaching pharmacy schools with hospitals similar to medical schools so that pharmacy students may be able to practice their clinical knowledge in patient care and improve their clinical skills [37-41]. Moreover, PharmD graduates must be given extensive duties in the clinical pharmacy services so that they can progress and play their role as healthcare professionals effectively [43].

Apart from traditional pharmacy roles, pharmacists must assume the clinical role that contemporary healthcare service demands. Khan and colleagues highlighted that most doctors in Pakistan do not consider pharmacist as an integral member of allied healthcare team [42, 43]. There is a need to increase their awareness regarding the role pharmacists could play in Pakistan's healthcare system. Evidence highlights that pharmacist's inclusion in disease management as member of allied health team have improved patients' treatment outcomes [44]. Randomized controlled trials involving pharmacist - driven pharmaceutical care model in Pakistani patients with chronic illnesses such as diabetes, hypertension, rheumatoid arthritis, etc., have shown significant improvements in treatment outcomes [44-47]. This evidence base would improve pharmacists' standing in healthcare. In addition, allowing clinical pharmacists to accompany allied health members during clinical rounds and participation of pharmacists in continuous medical education activities alongside other healthcare professionals would be beneficial for recognition of pharmacists as a clinical member of allied health team. Additionally, spreading awareness about pharmacist's role through regional and national pharmacy societies would also highlight pharmacists and their responsibilities among health professionals and public.

Furthermore, pharmacists would have to increase patient awareness about their role. They would have to perform their role as disease educator and counsellor. The patients would not be able to understand the impact a pharmacist could make in healthcare system unless the pharmacists take initiative. Patient education and counselling may not be clinically effective if the pharmacists do not have pharmaceutical care skills [22]. Therefore, it is essential to teach these skills to pharmacy students in PharmD curriculum and provide them with opportunities to practice during summer attachments or experiential training $[22,39]$. This would be helpful as the pharmacy students would assume the role of pharmacists in future. There is a need to add provision of a counselling room in regulations for healthcare settings as this would provide opportunity for dissemination of information regarding disease and therapy. Moreover, such provision would enhance patient satisfaction and improve the recognition of pharmacists as a patient care provider [22, 39, 42, 43].

\section{Limitations of the study}

The results of this study may be interpreted with caution as pharmacist from primary care hospitals, and community pharmacies were not included. Therefore, the findings of this study reflect the opinion of pharmacists from clinical settings only. The views may differ among pharmacist based on workplace. The study was a surveybased research and involved close-ended questions. Qualitative studies could investigate extensively and may provide in-depth explanation of expectations as well as experiences of pharmacists within the healthcare system of Pakistan.

\section{Conclusion}

Pharmacists in Pakistan are willing to perform their duties and provide direct patient care using their clinical knowledge and expertise, pharmaceutical care skills and, experience for medicines management. It was observed that the updated curriculum improved their clinical knowledge and health policy regulations have provided more opportunities of pharmacists to collaborate with doctors in patient care. However, they seemed sceptical of performing advanced clinical pharmacy roles such as 
intervening in prescriptions and medication therapy, consultations, prescribing, etc. This scepticism was mainly due to a prevalent negative perception about pharmacists' clinical capabilities among most doctors.

It is essential to integrate pharmacists' clinical rotations with doctors to inculcate a professional relationship. Moreover, it would be helpful if training and seminars are conducted on the importance of clinical pharmacy services in Pakistan's healthcare system. Such activities would provide an opportunity to recognize the accomplishments as well as identify limitations of pharmacists' clinical role. Further studies are recommended to explore the concerns of pharmacists regarding these services so that they can be adequately addressed.

\section{Supplementary information}

Supplementary information accompanies this paper at https://doi.org/10. 1186/s12913-020-05459-0.

\section{Additional file 1.}

\section{Abbreviations}

SPSS: Statistical Package for Social Sciences; USA: United States of America; Pharm.D: Doctor of Pharmacy; KPK: Khyber Pakhtunkhwa; AJK: Azad Jammu \& Kashmir; WHO: World Health Organization; ACCP: American College of Clinical Pharmacy

\section{Acknowledgements}

We extend our gratitude to all the participants for their contribution in the study. We acknowledge the support of Khan and colleagues from Pakistan in completing the data collection.

\section{Authors' contributions}

NK conceived the idea and designed the study with KM. NK and AA and MS wrote the introduction. NK collected and entered the data in SPSS with AA. $\mathrm{NK}$ and $\mathrm{KM}$ analysed the data and wrote the results section with assistance from $A A, Z H$ and MS. NK and AA formulated the tables in results section. AA assisted discussion and conclusion writing with NK, MS, ZH and KM. Methods section was written by NK with assistance from AA and MS. AA, NK, MS and $\mathrm{ZH}$ significantly contributed to the revision of the manuscript. Whole work was supervised by KM. All authors read and approved final manuscript.

\section{Funding}

No funding was sought for this study.

\section{Availability of data and materials}

The datasets used and/or analysed during the current study available from the corresponding author on reasonable request.

\section{Ethics approval and consent to participate}

The study was approved by Ethics Committee of University of Sunderland, UK. Based on this approval, the study was approved by the Institutional Review Board of Clifton Hospital Karachi, Pakistan (Reference\#10-17). The respondents were explained about the study at the time of invitation. They were informed that their participation was voluntary and were sought an informed written consent for participation as well as publishing their responses.

\section{Consent for publication}

Not applicable.

\section{Competing interests}

The authors declared that they have no competing interests.

\section{Author details}

'School of Pharmacy and Pharmaceutical Sciences, University of Sunderland, Sunderland, UK. ${ }^{2}$ Faculty of Technology, School of Computer Science, University of Sunderland, Sunderland, UK. ${ }^{3}$ Department of Pharmacy Practice, College of Clinical Pharmacy, Imam Abdulrahman Bin Faisal University, Dammam, Saudi Arabia. ${ }^{4}$ Department of Clinical Pharmacy, College of Pharmacy, Prince Sattam bin Abdulaziz University, Alkharj, Saudi Arabia. ${ }^{5}$ Department of Health and Science Management, Bahria University, Karachi, Pakistan.

Received: 21 October 2019 Accepted: 24 June 2020

Published online: 02 July 2020

\section{References}

1. Rosenthal MM, Breault RR, Austin Z, Tsuyuki RT. Pharmacists' self-perception of their professional role: insights into community pharmacy culture. J Am Pharm Assoc. 2011;51:363-7.

2. McGivney MS, Meyer SM, Duncan-Hewitt W, DL H, JVR G, Smith RB. Medication therapy management: its relationship to patient counseling, disease management, and pharmaceutical care. J Am Pharm Assoc. 2007;47: 620-8.

3. Rossing C, Hansen EH, Traulsen JM, Krass I. Actual and perceived provision of pharmaceutical care in Danish community pharmacies: the pharmacists' opinions. Pharm World Sci. 2005;27:175-81.

4. Martin-Calero MJ, Machuca M, Murillo MD, Cansino J, Gastelurrutia MA, Faus MJ. Structural process and implementation programs of pharmaceutical care in different countries. Curr Pharm Des. 2004;10:3969-85.

5. Tice L. 2002 white paper on pharmacy technicians: needed changes can no longer wait. J Manag Care Pharm. 2003;9:72-83.

6. Strand LM, Cipolle RJ, Morley PC, Frakes MJ. The impact of pharmaceutical care practice on the practitioner and the patient in the ambulatory practice setting: twenty-five years of experience. Curr Pharm Des. 2004;10:3987-4001.

7. Awad A, Al-Ebrahim S, Abahussain E. Pharmaceutical care services in hospitals of Kuwait. J Pharm Pharm Sci. 2006;9:149-57.

8. Worley MM, Schommer JC, Brown LM, Hadsall RS, Ranelli PL, Stratton TP, Uden DL. Pharmacists' and patients' roles in the pharmacist-patient relationship: are pharmacists and patients reading from the same relationship script? Res Social Adm Pharm. 2007;3:47-69.

9. Hepler CD, Strand LM. Opportunities and responsibilities in pharmaceutical care. Am J Hosp Pharm. 1990;47:533-43.

10. Farris KB, Fernandez-Llimos F, Benrimoj SI. Pharmaceutical care in community pharmacies: practice and research from around the world. Ann Pharmacother. 2005;39:1539-41.

11. van Mil JWF. Pharmaceutical care, the future of pharmacy: theory, research, and practice. Published 2000. https://www.rug.nl/research/portal/files/14524 956/thesis.pdf. (date last accessed 2 Mar 2020).

12. Zammit D. How to make ethical decisions. Pharm J. 2003;271:16.

13. Nishtar S, Boerma T, Amjad S, Alam AY, Khalid F, UI Haq I, Mirza YA. Pakistan's health system: performance and prospects after the 18th constitutional amendment. Lancet. 2013;381:2193-206.

14. Naqvi AA, Zehra F, Naqvi SBS, Ahmad R, Ahmad N, Usmani S, Badar S, Younus I, Khan SJ. Migration trends of pharmacy students of Pakistan: a study investigating the factors behind brain drain of pharmacy professionals from Pakistan. Ind J Pharma Educ Res. 2017;51(2):192-206. https://doi.org/ 10.5530/ijper.51.2.25

15. Awan MU, Raouf A, Ahmad N, Sparks L. Total quality management in developing countries: a case of pharmaceutical wholesale distribution in Pakistan. Int J Pharm Healthc Mark. 2009;3:363-80.

16. Stewart $D$, Letendre DE. The pharmacy education: a historical perspective. In: Fathelrahman A, Ibrahim Ml, Alrasheedy A, Wertheimer A, editors. Pharmacy education in the twenty first century and beyond. London: Academic Press; 2018. p. 11-20.

17. Ahmed A, Tanveer M, Siddiqui A, Khan GM. Bridging the gap for clinical pharmacist in developing countries like Pakistan. J Coll Physicians Surg Pak. 2018:28:229-32.

18. Naqvi AA, Zehra F, Khan N, Ahmad R, McGarry K. Interactions and conflicts of interests between prescribers and medical sales representatives (MSRs) regarding prescribing and drug promotion practices in Karachi, Pakistan. Pak J Pharm Sci. 2019;32(2):687-95.

19. Aziz MM, Fang Y, Babar ZU, Usman M. Hospital pharmacy services in Pakistan. Eur J Hosp Pharm. 2017;24:253. 
20. Khowaja K. Healthcare systems and care delivery in Pakistan. J Nurs Adm. 2009;39:263-5. https://doi.org/10.1097/NNA.0b013e3181a96473.

21. Naqvi AA, Naqvi SBS, Zehra F, Verma AK, Usmani S, Badar S, Ahmad R, Ahmad N. Estimation of the direct cost of poliomyelitis rehabilitation treatment to Pakistani patients: a 53-year retrospective study. Appl Health Econ Health Policy. 2018;16:871-88. https://doi.org/10.1007/s40258-018-0422-6.

22. Naqvi AA, Hassali MA, Naqvi SBS, Aftab MT, Zehra F, Nadir MN, Jahangir A, Kachela B. Assessment of patient satisfaction following pharmacist counselling session by a novel patient satisfaction feedback on counselling questionnaire. JPHSR. 2019;10:243-54. https://doi.org/10.1111/jphs.12294.

23. Azhar S, Hassali MA, Mohamed Ibrahim MI. Doctors' perception and expectations of the role of the pharmacist in Punjab, Pakistan. Trop J Pharm Res. 2010;9:205-22.

24. Khan MU, Khan AN, Ahmed FR, Feroz Z, Rizvi SA, Shah S, Hussain R, Adil Z. Patients' opinion of pharmacists and their roles in health care system in Pakistan. J Young Pharm. 2013;5:90-4.

25. Pakistan Pharmaceutical Country Profile. World Health Organization. https://www who.int/medicines/areas/coordination/pakistan.pdf. Accessed 15 Mar 2020.

26. Sample size calculator. Raosoft. http://www.raosoft.com/samplesize.html. Accessed 14 Mar 2020

27. Lawshe $\mathrm{CH}$. A quantitative approach to content validity. Pers Psychol. 1975; 28:563-75.

28. Rungtusanatham M. Let's, not overlook content validity. Decision Line. 1998. p. 10-3. http://file.qums.ac.ir/repository/snm/Let\%E2\%80\%99s\%20Not\%2 00verlook\%20Content\%20Validity.pdf.

29. Cohen JS. Statistical power analysis for the behavioral sciences. 2nd ed; 1998.

30. De Vellis RF. Scale development: theory and applications. 26th ed; 1991.

31. Banerjee A, Chitnis UB, Jadhav SL, Bhawalkar JS, Chaudhury S. Hypothesis testing, type I and type II errors. Ind Psychiatry J. 2009;18(2):127-31. https:// doi.org/10.4103/0972-6748.62274.

32. Agresti A. Introduction to categorical data analysis. New York: Wiley; 1996.

33. Scahill SL, Atif M, Babar ZU. Defining pharmacy and its practice: a conceptual model for an international audience. Integr Pharm Res Pract. 2017;6:121-9.

34. Smith F. Community pharmacy in Ghana: enhancing the contribution to primary health care. Health Policy Plan. 2004;19:234-41.

35. Jesson J, Bissell P. Public health and pharmacy: a critical review. Crit Public Health. 2006;16:159-69.

36. Goel P, Ross-Degnan D, Berman P, Soumerai S. Retail pharmacies in developing countries: a behavior and intervention framework. Soc Sci Med. 1996;42:1155-61.

37. Bhagavathula AS, Sarkar BR, Patel I. Clinical pharmacy practice in developing countries: focus on India and Pakistan. Arch Pharma Pract. 2014:5:91.

38. Abbas A. The Catch-22 of pharmacy practice in Pakistan's pharmacy education. Pharmacy. 2014;2:202-4. https://doi.org/10.3390/ pharmacy2030202

39. Abbas A. Evidence based improvements in clinical pharmacy clerkship program in undergraduate pharmacy education: the Evidence Based Improvement (EBI) initiative. Pharmacy. 2014;2:270-5. https://doi.org/10. 3390/pharmacy2040270.

40. Azhar S, Hassali MA, Ibrahim MI, Ahmad M, Masood I, Shafie AA. The role of pharmacists in developing countries: the current scenario in Pakistan. Hum Resour Health. 2009;7:54

41. Azhar S, Hassali MA, Ibrahim MI. Perceptions of hospital pharmacist's role in Pakistan's healthcare system: a cross-sectional survey. Trop J Pharm Res. 2011;10:11-7.

42. Khan A. 15th international pharmacy conference and exhibition. Lahore: Pakistan Pharmacists Association; 2009.

43. Khan N, McGarry K, Naqvi AA, Holden K. Doctors' perceptions, expectations and experience regarding the role of pharmacist in hospital settings of Pakistan. Int J Clin Pharm. 2020. https://doi.org/10.1007/s11096-020-00991-9.

44. Khan N, Abbas A. Clinical trials involving pharmacists in Pakistan's healthcare system: a leap from paper to practice. Pharmacy. 2014;2:244-7. https://doi. org/10.3390/pharmacy2030244

45. Naqvi AA, Hassali MA, Naqvi SBS, Aftab MT. Impact of pharmacist educational intervention on disease knowledge, rehabilitation and medication adherence, treatment-induced direct cost, health-related quality of life and satisfaction in patients with rheumatoid arthritis: study protocol for a randomized controlled trial. Trials. 2019;20:488. https://doi.org/10.1186/s13063-019-3540-z
46. Bukhsh A, Nawaz M, Ahmed HS, Khan TM. A randomized controlled study to evaluate the effect of pharmacist-led educational intervention on glycemic control, self-care activities and disease knowledge among type 2 diabetes patients: A consort compliant study protocol. Medicine (Baltimore). 2018;97:e9847

47. Saleem F, Hassali MA, Shafie AA, UI Haq N, Farooqui M, Aljadhay H, Ahmad FU. Pharmacist intervention in improving hypertension-related knowledge, treatment medication adherence and health-related quality of life: a nonclinical randomized controlled trial. Health Expect. 2015;18:1270-81.

\section{Publisher's Note}

Springer Nature remains neutral with regard to jurisdictional claims in published maps and institutional affiliations.
Ready to submit your research? Choose BMC and benefit from:

- fast, convenient online submission

- thorough peer review by experienced researchers in your field

- rapid publication on acceptance

- support for research data, including large and complex data types

- gold Open Access which fosters wider collaboration and increased citations

- maximum visibility for your research: over $100 \mathrm{M}$ website views per year

At BMC, research is always in progress.

Learn more biomedcentral.com/submissions 